\title{
Paisagens urbanas comuns: sob constante pressão de interesses corporativos
}

Paysages urbains communs: sous la pression constante des intérêts des entreprises

Paisajes urbanos comunes: bajo constante presión de intereses corporativos Common urban landscapes: under constant pressure of corporate interests

Jefferson Tomaz de Araújo, Karina Martins de Souza e Eloisa Carvalho de Araujo

\section{(2) OpenEdition} Journals

Edição electrónica

URL: http://journals.openedition.org/espacoeconomia/5721

DOI: $10.4000 /$ espacoeconomia.5721

ISSN: 2317-7837

Editora

Núcleo de Pesquisa Espaço \& Economia

Refêrencia eletrónica

Jefferson Tomaz de Araújo, Karina Martins de Souza e Eloisa Carvalho de Araujo, « Paisagens urbanas comuns: sob constante pressão de interesses corporativos », Espaço e Economia [Online], 14 | 2019, posto online no dia 11 agosto 2019, consultado o 06 setembro 2019. URL : http:// journals.openedition.org/espacoeconomia/5721; DOI : 10.4000/espacoeconomia.5721

Este documento foi criado de forma automática no dia 6 Setembro 2019

(C) NUPEE 


\title{
Paisagens urbanas comuns: sob constante pressão de interesses corporativos
}

\author{
Paysages urbains communs: sous la pression constante des intérêts des \\ entreprises \\ Paisajes urbanos comunes: bajo constante presión de intereses corporativos \\ Common urban landscapes: under constant pressure of corporate interests \\ Jefferson Tomaz de Araújo, Karina Martins de Souza e Eloisa Carvalho \\ de Araujo
}

\section{Apresentação}

1 As cidades contemporâneas estão se tornando cada vez mais diversificadas e multiculturais. Como medidas estruturais na arquitetura e na paisagem podem alterar o uso de uma área para que ela seja mais inclusiva? Como projetar paisagens urbanas que acolham as diferenças? A tendência observada em espaços urbanos que enfrentam desafios sociais vem por inspirar novos modelos para as políticas públicas municipais.

Com o propósito de antecipar uma discussão sobre a análise sensível do espaço, sua apropriação, dinamismos, conflitos e atores, assim como as inquietações do cotidiano, o presente artigo desenvolve-se a partir da aplicação de uma abordagem apoiada em estudos de caso em formato de um ensaio teórico. Estes possuem ênfase em uma metodologia que valoriza o debate conceitual sobre paisagens urbanas comuns, através de uma revisão bibliográfica que se aproxima do tema proposto frente a estudos empíricos.

Tomando como base a geografia cultural, a paisagem aqui se apresenta como produtora de significados. Segundo Cosgrove (1984, p.13), a paisagem nada mais é do que "um modo de ver o mundo". Nesse sentido, o que é valorizado é a experiência do ver, do olhar, do observar, do sentir. A paisagem, portanto, se apresenta como uma construção simultaneamente subjetiva e objetiva, plural e singular. 
O design de paisagens urbanas não deve se apoiar em fazer algo para grupos diferentes sob a ótica da segregação de espaços. Pelo contrário, o foco deve estar nas fronteiras e em sua capacidade de aproximar as diferenças, sem causar conflitos prejudiciais, podendo cada grupo desfrutar da presença um do outro, sem atrito.

\subsection{Orientação teórica inicial}

5 A revisão bibliográfica inicial baseou-se em um diálogo teórico orientado para a compreensão do espaço público enquanto elemento estruturante da paisagem. Carlos Nelson Ferreira dos Santos (1988), em sua obra "A cidade como um jogo de cartas", chama a atenção à importância da experiência da população na vida real no âmbito dos jogos de poder instituídos nas cidades. 0 autor elucida o poder que envolve vincular os projetos à materialidade, de modo que esse feito propicie de forma convincente a democratização do conhecimento sobre os espaços urbanos.

6 Por outro lado, Milton Santos (1996), na obra "A natureza do espaço: espaço e tempo, razão e emoção", proporciona uma reflexão sobre novas perspectivas relacionadas à ação espacial e social. Trata-se de uma teoria da ação, onde o espaço vivido é resultante da ação.

7 Já a luz das ideias de Harvey (2011) na obra "O Enigma do Capital e as crises do capitalismo", o autor destaca o poder que o capital exerce ao superar limites, frente a sua fluidez e flexibilidade. Ao valorizar visões de mundo, o autor ressalta algumas contradições do capital, tais como sua forma desigual de circular e de se alimentar de mercadorias, símbolos e representações no espaço urbano.

8 Margareth Pereira (2012), em seu artigo "Dimensões da experiência: espaço público, alteridade e lugar", alerta para o caráter fugidio da forma do espaço público, onde aspectos sociais, pessoais e coletivos se entrelaçam em uma trama marcada pela experiência da multidimensionalidade, ressaltando a incompletude da discussão entre espaço público e esfera pública.

9 E no intuito de desmistificar a ideia de um projeto vivo ligado ao nosso tempo, Jan Gehl, em sua obra "La humanización del Espacio Urbano" (2009), ressalta que a principal característica dos espaços urbanos deveria ser a de um lugar agradável em todos os aspectos. Onde todos os fatores - espaciais, físicos, sociais -, atuando de forma conjunta, podem resultar em uma sensação de bem-estar físico e psicológico.

10 Para Jordi Borja (2006), no artigo "Espaço público, condição da cidade democrática: a criação de um lugar de intercâmbio", as operações de transformação urbana do espaço público em seu formato híbrido, que compartilham investimentos públicos e privados, são as que melhor favorecem o desenvolvimento e a gestão destes espaços.

11 Na trilha da trajetória das teorias acima descritas para uma cidade complexa, que abriga uma sociedade igualmente complexa, as pesquisas em curso se apoiam em casos que buscam valorizar paisagens urbanas comuns sob constante pressão de interesses corporativos, e reafirmam a tese da mutabilidade das paisagens nas cidades contemporâneas.

12 Diante da temática introduzida, o artigo reacende a discussão sobre o conceito de comum, mas privilegia sua associação às paisagens urbanas. Segundo pesquisa realizada sobre o termo "commons ou comum" por Silveira e Savazoni (2018), o conteúdo e trajetória histórica do conceito sustentam-se em autores de diferentes correntes de pensamento e 
também em debates e ativismos relacionados. Ainda segundo os mesmos, o debate em questão expressa preocupação com temas como democracia, direito à cidade, cidade colaborativa, entre outros.

No Brasil, a utilização do conceito de comum tem sido objeto de atenção, sobretudo de ativistas e pesquisadores do campo da cibercultura, do meio ambiente e dos estudos sobre o direito à cidade e das comunidades tradicionais, sem que se possam registrar muitos autores produzindo conhecimento específico sobre o tema (SILVEIRA; SAVAZONI, 2018, p.02).

13 Ainda na trajetória da discussão do conceito, os autores apresentam diferentes abordagens relacionando-o, principalmente, a ambientes de luta em um contexto de um novo capitalismo. Ora valorizando não só a popularidade dos bens comuns, intrínsecos às práticas sociais; ora valorizando a necessidade dos mesmos de se libertarem dos rótulos do mercado, passíveis de não regulação. Em suma, o conceito expressa sua característica comunitária e política. É com base neste olhar que este artigo se desenvolve, observando e refletindo sobre práticas políticas, pelas lentes de paisagens urbanas comuns sob constante pressão de interesses corporativos.

14 As reflexões foram conduzidas pelo viés do enfraquecimento de simbolismos locais - a subtração impositiva de espaços públicos -, que traz à tona diversos questionamentos a respeito do modo com o qual a sociedade urbana capitalista é condicionada a desfrutar da sociabilidade na cidade contemporânea. Ou ainda, também pelo viés de como a cidade contemporânea trata seus espaços urbanos residuais - espaços dos possíveis de uso sociocultural -, suas apropriações, considerando a fronteira tênue entre necessidades e novas destinações de uso. Ressalta-se que o termo "espaços dos possíveis", segundo Bourdieu (1997), reflete espaços onde emergem vozes, dissonantes ou não, e aonde se desenrolam conflitos específicos. No presente artigo tal associação reafirma a condição desses espaços serem marcados, ora pela precariedade, ora pelo potencial de uso.

Nesse sentido, o artigo foi estruturado em quatro seções. Na primeira seção a narrativa buscou contribuir para a reflexão sobre as paisagens urbanas comuns, suas diferenças, assim como pressões observadas pelos interesses corporativos. Este tópico de apresentação e orientação teórica inicial adquire a perspectiva de antecipar uma discussão apoiada em pesquisas em curso quanto à análise sensível do espaço. A segunda seção procurou abordar a análise da subtração impositiva de espaços públicos - a partir do caso da Praça Carlos Gianelli na cidade de São Gonçalo/RJ -, explicitando com base em reflexões teóricas, possíveis estratégias e conflitos observados, assim como representações simbólicas e novas sociabilidades potenciais. A terceira seção buscou apoiar-se em uma análise crítica que privilegiou o debate da cidade contemporânea e seus espaços residuais. Ainda neste tópico, os espaços residuais foram apresentados como espaços dos possíveis, potenciais às apropriações espontâneas, mostrando-se como formas de resistência. Entretanto, apresentados também permeáveis a interesses corporativos e frutos de inquietações do cotidiano. Por fim, na quarta e última seção, o artigo destacou a oportunidade e o desafio de tratar do tema das paisagens urbanas comuns sob pressão dos interesses corporativos, na perspectiva de novos olhares somarem-se às reflexões aqui apresentadas. 


\section{A subtração impositiva de espaços públicos urbanos: o caso da Praça Carlos Gianelli}

16 A produção do espaço urbano, as camadas de estratificação social e a composição da paisagem são reflexos de períodos distintos pelos quais as cidades atravessaram ao longo do seu processo evolutivo. A forma urbana possui expressões estética e funcional, sendo determinadas pelas ideologias em voga no período de (re)organização da sociedade (SANTOS, 1988).

O papel dos agentes sociais na construção do espaço urbano é regido por constantes disputas que imprimem suas ideologias nas estruturações espacial e simbólica da cidade. Dessa maneira, a estrutura urbana reflete o resultado do confronto, as materialidades e signos diversos impregnados ao espaço (CORRÊA, 1993; SANTOS, 1988).

18 Na cidade contemporânea neoliberal as práticas do Estado, em consonância a diversos interesses privados, estimulam os fluxos flexíveis de reprodução do capital nos negócios urbanos, nos quais o capital se alimenta de mercadorias, símbolos e representações espaciais favoráveis à acumulação capitalista no espaço (HARVEY, 2011). Essas dinâmicas acentuam os confrontos entre os sujeitos, condicionam novas formas de desenvolvimento da sociedade, acentuam as disparidades socioespaciais e engendram novos significados aos espaços urbanos da cidade capitalista.

19 Nesse contexto, se insere o bairro Alcântara em São Gonçalo, Região Metropolitana do Rio de Janeiro. Alcântara detém um forte caráter comercial e de prestação de serviços como componente vital à economia do município. Esse rearranjo econômico da cidade se deu, especialmente a partir da década de 1980, como um dos desdobramentos do processo de desindustrialização gonçalense (ARAUJO; MELO, 2014). A centralidade exercida por Alcântara é, aliada ao Centro da cidade, o coração econômico de São Gonçalo, adquirindo dessa maneira, grande atratividade às atividades comerciais e à dinâmica imobiliária. Diante desse cenário de visibilidade político-econômica, uma praça pública no centro urbano de Alcântara sofreu um processo de desafetação e concessão do direito real de uso à iniciativa privada em 2008 (CAMPAGNANI, 2011), onde foi construído um shopping center no início desta década.

20 A Praça Carlos Gianelli se configurava como um importante ponto nodal e centralidade imagética de um centro urbano num bairro fortemente valorizado pelo seu expressivo caráter comercial (Imagem 1). A praça se configurou por muitas décadas como o locus de uma multiplicidade de eventos, relações e dinâmicas. Um diverso arranjo de relações sociais, manifestações políticas, expressões culturais e atividades econômicas compunham o valor simbólico daquela paisagem consolidada historicamente, em paralelo à história urbana de São Gonçalo. Uma profusão de fluxos efervescentes compunha aquela paisagem, do mesmo modo que o simbolismo da imagem da praça aliada à igreja católica adjacente já havia sido consolidado no campo imagético da população no processo cognitivo da legibilidade do espaço (LYNCH, 1960). 
Imagem 1 - Praça Carlos Gianelli em Alcântara, década de 1970.

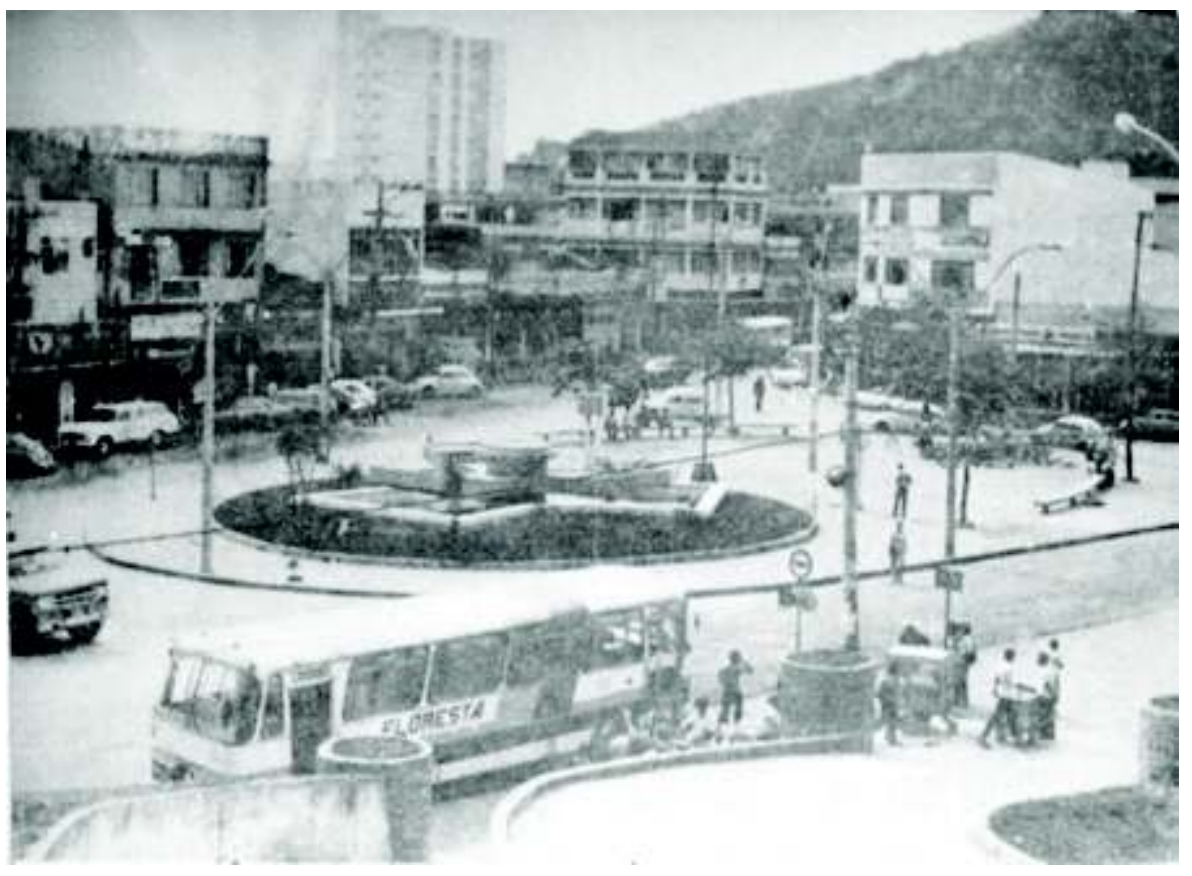

Fonte: Acervo MEMOR - Autor desconhecido.

$21 \mathrm{Na}$ conjuntura contemporânea, a negligência do Estado permitiu que aquele espaço público de grande visibilidade sofresse um intenso processo de sucateamento com o abandono de investimentos públicos e ausência de manutenção. Consequentemente, a praça tornou-se associada a uma imagem de deterioração, insegurança pública e obsolescência espacial (TAVARES, 2013). Desse modo, criou-se um estigma de necessidade de renovação espacial em função das dinâmicas neoliberais e dos sujeitos interessados, permitindo assim, uma arbitrária reurbanização e ressignificação daquele espaço.

Apesar de um processo judicial conturbado, a completa subtração e privatização do espaço público foi coroada com a inauguração do Shopping Pátio Alcântara em novembro de 2013 (Imagem 2). Contudo, mesmo antes disso, as estratégias de divulgação do empreendimento se calcavam na sua proximidade com o novo polo do Complexo Petroquímico do Estado do Rio de Janeiro (COMPERJ) no município de Itaboraí/RJ adjacente a São Gonçalo - e, especialmente, nas amenidades urbanas oferecidas pelo centro urbano consolidado de Alcântara. 
Imagem 2 - Shopping Pátio Alcântara concluído em 2013: obstruções físicas e visuais.

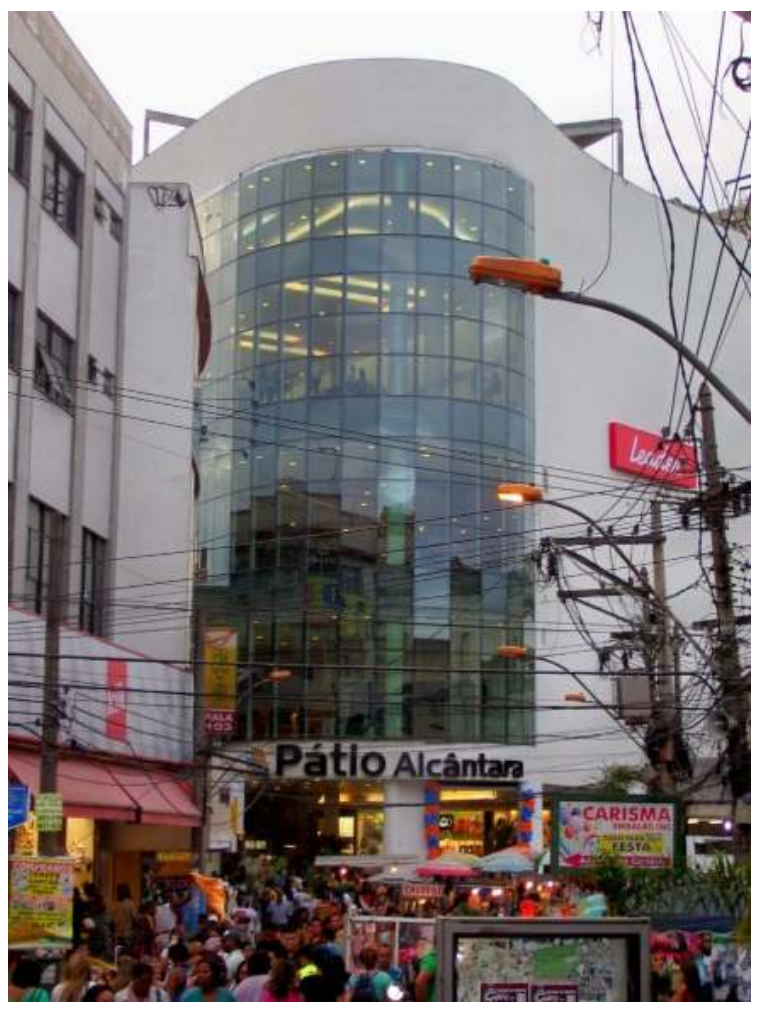

Fonte: Vagner Rosa/Blog Território Gonçalense, 2013

23 Nesse entendimento, as estratégicas mercadológicas arraigadas num processo de valorização fundiária, fruto do COMPERJ, contribuíram à atratividade do mercado imobiliário no cenário gonçalense. Esse fato ratifica a intensificação das práticas neoliberais naquele núcleo de grande visibilidade e atratividade à reprodução do capital. As medidas ocorridas àquele espaço se aproximam da tese da cidade tratada como mercadoria em função dos interesses de determinados agentes sociais na reconfiguração espacial e simbólica de um espaço público urbano (Imagem 3). 
Imagem 3 - Fragmentações simbólicas e espaciais do Shopping Pátio Alcântara e seu entorno.

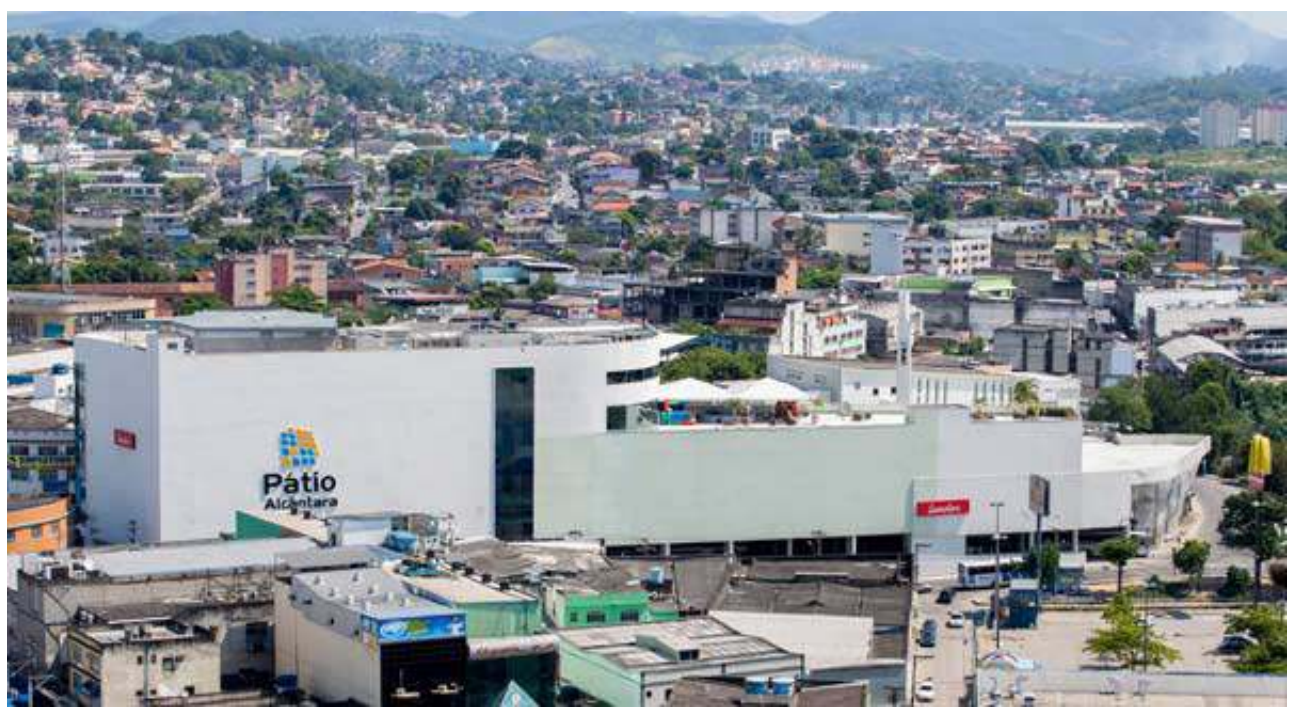

Fonte: <https://www.guiadasemana.com.br/rio-de-janeiro/compras/estabelecimento/patio-alcantara>

\subsection{Simbolismos e novas sociabilidades}

O espaço público pode ser visto por Bauman (2007) como o espaço da diferença, onde a experiência de conviver com o estranho deve se fazer presente. Desse modo, é no espaço público que a possibilidade de interação social entre grupos distintos deve se manifestar em face à diversidade social que compõe a paisagem das cidades. Para Queiroga e Bennefati (2007, p. 85), o espaço público é entendido não apenas como um suporte físico onde as ações da esfera pública são realizadas, mas também como o espaço da esfera pública. Na visão de Serpa (2007), o espaço público é "compreendido, sobretudo, como o espaço da ação política ou, ao menos, da possibilidade de ação política na contemporaneidade" (SERPA, 2007, p. 09).

A contribuição de Borja e Muxí (2001) vai ao encontro das visões supracitadas, na qual os autores defendem o espaço público como palco da cidadania e diretriz essencial ao ordenamento da paisagem. $O$ espaço público fomenta a diversidade de usos e funções em suas bordas, permite manifestações sociopolíticas e culturais, possibilita encontros cotidianos e estimula vínculos aos lugares urbanos. 0 espaço público é, por excelência, o espaço da coexistência de grupos sociais distintos (BORJA; MUXÍ, 2001).

Nessa perspectiva, percebe-se o valor singular dos espaços públicos na composição da paisagem urbana. Borja (2006) comenta sobre a face pública oculta de determinados espaços efêmeros e a potencialidade de afirmação do seu caráter público. 0 autor embasa essa afirmação principalmente por meio de exemplos que clarificam a apropriação social desses espaços como fruto de atividades comerciais ali instaladas. Desse modo, pode-se salientar a relação simbiótica entre espaço público e atividade comercial nas cidades capitalistas. Nesse cenário, portanto, é possível inferir que o consumo emerge como uma variável crucial ao uso e apropriação dos espaços públicos na cidade contemporânea.

No bojo da modernidade, o turbilhão de mudanças sociais no espaço e no tempo marca a reconfiguração da vida moderna na sociedade capitalista. A efemeridade, o fugidio e a fragmentação emergem como um retrato característico da sociedade moderna e suas 
práticas na vida urbana (BAUMAN, 2001; HARVEY, 2008). A ideologia da condição moderna se reflete principalmente na dificuldade de preservação do sentido de continuidade histórica e da memória das cidades. Esse fato se dá especialmente em função da obsolescência programada dos espaços inerente ao capitalismo neoliberal: a destruição criativa, fruto das dinâmicas mercadológicas contemporâneas que se relaciona às crises cíclicas de superacumulação do capital no espaço (HARVEY, 2008, p. 22)

Richard Sennett salienta que os novos padrões culturais da sociedade moderna trazem consigo a priorização da intimidade e da privacidade na vida urbana. Para o autor, a propagação dessa individualização narcisista contribui significativamente ao retraimento da vida pública. Por sua vez, o individualismo do sujeito moderno é refletido nos projetos arquitetônicos e urbanísticos, os quais detêm características favoráveis ao consumo em detrimento da sociabilidade nos espaços públicos e coletivos (SENNETT, 2001).

A expansão da sociedade de consumo permitiu uma profunda alteração nos sistemas de produção, nas relações comerciais e no próprio modelo econômico capitalista. Essa transição estrutural se reflete claramente nas relações sociais e, por conseguinte, na apropriação do espaço público. Os novos padrões de consumo da sociedade capitalista neoliberal instigam o individualismo, a homogeneização de grupos sociais nos espaços "públicos" voltados ao consumo e a prática de novas sociabilidades artificiais (CORRÊA, 2013; HARVEY, 2008).

$30 \mathrm{Na}$ atmosfera da segunda metade do século $\mathrm{XX}$, o consumismo exacerbado emerge como atividade de lazer sob a ótica do ideal de modernidade (AUGUSTIN, 2001). A efervescência de complexos condominiais privados, shopping centers e demais espaços de lazer vinculados ao consumo instiga novas práticas de sociabilidade na sociedade contemporânea. Para Sorkin (1992), a funcionalidade e a magnitude desses espaços "a la Disneyland" contribuem significativamente à estratificação social no espaço urbano e ao enfraquecimento da vida pública na cidade.

Boa parte dos integrantes dessas classes médias, notadamente aqueles situados num patamar de alto poder aquisitivo, integram-se cada vez mais a um modo de vida que se traduz, nas metrópoles, num padrão funcional caracterizado por uma espécie de 'circuito', incluindo 'moradias fechadas', trabalhos em complexos empresariais, consumo em supermercados, shoppings, circulação em veículos particulares, etc. Articula-se neles um modo de vida distinto, segregado e diferenciado, evitando o máximo possível o contato com espaços públicos e sua diversidade de grupos sociais (FRÚGOLI JR., 1995, p. 76).

31 Os elementos arquitetônicos símbolos do consumismo capitalista abarcam em si a criação de cenários favoráveis à constante reprodução do capital no espaço urbano. O shopping center enquanto exímio espaço de consumo traz em seus conceitos a "cenarização" de espaços urbanos enclausurados e a artificialização da sociabilidade entre os sujeitos, os quais se tornam meros consumidores em seus espaços "públicos" de circulação (CORRÊA, 2013).

32 A mercantilização de um espaço público de grande visibilidade espacial, centralidade sociológica e atratividade econômica sugere a ressignificação dos espaços da cidade contemporânea em função dos interesses mercadológicos neoliberais. A legibilidade de um espaço intrínseca ao campo cognitivo da população e sua atratividade às pressões corporativas parecem se despontar como variáveis estratégicas à criação de novos simbolismos locais diante das práticas de mercado. 
ato de se edificar um shopping center sobre uma praça pública transcende a ideia de desativação de um uso "obsoleto". As características e atributos urbanísticos - tanto em sua dimensão física quanto abstrata - daquele sítio urbano sugerem a permanência simbólica de alguns dos valores da praça no espaço do shopping. As características de marco local do centro de bairro, espaço de atividades sociais e ponto de encontros cotidianos entre indivíduos foram arbitrariamente subtraídas de um espaço público e transferidas a um espaço privado. Em um contexto de fortes disputas entre os sujeitos sociais no espaço urbano, a praça foi subtraída fisicamente da população e indica a possibilidade ter sido substituída simbolicamente por um espaço onde o lazer é travestido em forma de consumo.

ação de ícones locais, cenários emblemáticos, paisagens artificiais, pseudo lugares e espaços "higienizados" revela o alinhamento de determinados agentes sociais em prol da (re) produção do espaço aos moldes dos negócios urbanos da cidade capitalista neoliberal. Para Corrêa (2013), a "paisagem da simulação" do shopping center se trata de um simbolismo espacial fixo do capitalismo. Por sua vez, a força desse símbolo traz consigo a tentativa de reprodução de um ambiente genérico e a manipulação programada do espaço/tempo em prol do lucro.

[...] capta-se o sentido ideológico das formas simbólicas existentes nos shopping centers. Esse sentido é escamotear o estímulo para se comprar mais, tornando o ato da compra livre de possíveis sentimentos de culpa, levando a se considerar o shopping center não apenas o local de compras, mas também de entretenimento, lazer, convivência social, cultura e civilidade. A ideologia faz crer que se trata de um espaço público, limpo, seguro, livre dos perigos existentes fora de sua área privada e controlada (CORRÊA, 2013, p. 96).

Dessa maneira, os aspectos culturais e identitários de um espaço público suprimido parecem emergir de forma ressignificada, com restrição de usos e práticas de exclusão de determinados grupos sociais no espaço privatizado. $\mathrm{O}$ uso e a apropriação do novo espaço de "lazer" são garantidos àqueles sujeitos que detém capital disponível à possibilidade do consumo. A referida prática suscita um dos favoritos ideais neoliberais na contemporaneidade: a exclusão socioespacial pelo poder de consumo.

\section{A cidade contemporânea e seus espaços residuais}

O espaço residual comumente considerado como sobra da urbanização e como algo a ser corrigido é apontado, neste trabalho, como um espaço que perdeu a sua identidade e que se apresenta excluído da vivência da cidade (FERRARA, 2000). Apesar de poder ser um espaço privado, os espaços residuais, em sua maioria, são espaços públicos que perderam o seu caráter de coletividade. Encontram-se aparentemente esquecidos, não percebidos, não utilizados ou subutilizados por grande parte da sociedade.

A análise sensível desses espaços está diretamente conectada com a questão da percepção, também presente em conceitos afins. $O$ termo espaço residual só começou a surgir nos discursos acadêmicos e profissionais nas últimas quatro décadas, frequentemente aludido por vários autores como sinônimo desses conceitos correlatos. Dentre os mais difundidos e que, na maioria dos casos, são utilizados como se representassem o mesmo significado de espaço residual, temos o conceito de vazio urbano (BORDE, 2006), terrain vague (SOLÀ-MORALES, 2003) e espaço-lixo (KOOLHAAS, 2010). 
vio urbano é relacionado, usualmente, a áreas desocupadas na estrutura da cidade Essas áreas são "terrenos e edificações desafetados, subutilizados, desocupados ou desestabilizados localizados em terrenos consolidados e infraestruturados que passaram, ou estão passando, por um processo de esvaziamento, o vazio esvaziado" (BORDE, 2006, p. 13). Entretanto, os espaços residuais vão além de terrenos e edificações, podem ser parte da malha viária, calçadas, barreiras físico-sociais, dentre outros.

Com relação ao termo terrain vague, pode-se notar a inexistência de uma memória atual do espaço, mas sua substituição por uma memória do passado. $O$ passado se sobrepõe ao presente. Os terrain vagues, de acordo com o idealizador do conceito, são:

[...] lugares aparentemente esquecidos, onde parece predominar a memória do passado sobre o presente. São lugares obsoletos nos que somente certos valores residuais parecem se manter apesar de sua completa desafeição da atividade da cidade. São, em definitiva, lugares externos, estranhos, que ficam foram dos circuitos, das estruturas produtivas... São suas bordas carentes de uma incorporação eficaz, são ilhas interiores esvaziadas de atividade, são olvidos e restos que permanecem fora da dinâmica urbana. Convertendo-se em áreas simplesmente des-habitadas, in-seguras, in-produtivas. Em definitiva, lugares estranhos ao sistema urbano, exteriores mentais no interior físico da cidade que aparecem como contra imagem da mesma, tanto no sentido de sua crítica como no sentido de sua possível alternativa (SOLÀ-MORALES, 2003, p. 188).

40 Já os espaços residuais pertencem ao momento atual. Foram produzidos por alguma dinâmica urbana do passado, mas mantém seu caráter de resíduo devido a não conexão com a vivência urbana existente no momento. Vale ressaltar ainda que os espaços residuais não são espaços estranhos aos usuários da cidade. São espaços comuns, usuais, com os quais nos deparamos todos os dias, por mais que não lhes demos a devida atenção. São sobras permeadas por cidade, pertencentes ao senso comum.

Por último, podemos notar que o espaço residual não se limita ao conceito de espaço-lixo, como sendo o resíduo deixado pela humanidade sobre o planeta (KOOLHAAS, 2010). No entanto, o citado espaço residual muito se alimenta deste conceito:

o produto construído [...] da modernização [...] é [...] o espaço-lixo. [...] é o que resta depois da modernização seguir o seu curso, ou mais concretamente o que se coagula enquanto a modernização está em marcha, o seu resíduo (KOOLHAAS, 2010, p.69).

Os resíduos sempre foram um "problema" a ser corrigido e essa situação se intensifica na cidade contemporânea. Vale ressaltar a produção de espaços residuais no contexto contemporâneo, principalmente, relacionada às grandes renovações urbanísticas. Segundo Balbi (2017), eles são produtos de um processo de construção e de reconstrução urbana sem fim: "[...] os verbos que começam por <re> produzem espaço-lixo" (KOOLHAAS, 2010, p.91) e produzem espaços residuais.

43 Esses espaços têm se tornado um desafio urbano ainda maior, devido ao intenso processo de migração do campo para a cidade e às rápidas mutações da atualidade. Como Ascher (2010) ressalta, a cidade construída possui dificuldade em acompanhar o ritmo acelerado das mudanças da sociedade, do conhecimento e da tecnologia. Contudo, a persistente presença desses espaços sem função ou subutilizados e deteriorados não cabe mais no contexto atual.

44 A cidade contemporânea e as forças que certificam a produção dessa cidade exigem uma resposta mais rápida. Os espaços residuais mostram-se como espaços de força e potência, que necessitam de ressignificação. Nesse contexto, eles precisam cumprir uma função, 
seja ela social ou comercial. o uso comercial pode ser aplicado com o intuito de gerar capital para financiar outras intervenções urbanas.

Diante das possibilidades de apreensão da cidade contemporânea identificadas nesses resíduos, parte-se a seguir para uma análise sobre as intervenções à luz de interesses corporativos, que são ou podem vir a ser aplicadas nessa categoria de espaço.

\subsection{Espaços dos possíveis: entre necessidades e novas destinações de uso}

Os espaços residuais são espaços que se apresentam disponíveis a novos usos na cidade e que, conforme Ferrara (2000), são um desafio para a inventividade projetiva e podem ser um estímulo ao exercício da cidadania. Muitas apropriações espontâneas se mostram como formas de resistência desses espaços e apontam para o potencial de uso dos mesmos.

Em função dessas apropriações espontâneas surge o urbanismo tático, considerado neste trabalho como ações "ligadas à apropriação de espaços públicos subutilizados ou terrenos baldios pelas próprias populações locais. Na maioria das vezes elas envolvem a construção de protótipos urbanos de baixo custo, com natureza efêmera ou permanente." (NOGUEIRA, 2017, p.92).

As práticas do urbanismo tático carregam um potencial de criatividade, capaz de produzir espaços de uso e com significado. São maneiras de escapar do poder dominante, que visam um ajuste na estrutura física e social da cidade. 0 caráter do urbanismo tático como potencializador de políticas públicas, através de um comportamento cooperativo, relaciona-se à qualidade do espaço residual de ser um espaço do possível.

o potencial de uso destes resíduos apresenta-se também em diversos momentos através de apropriações informais de uso privado. Essas apropriações, muitas vezes, suprem a ausência de determinado comércio na região e, com o tempo, podem se consolidar na dinâmica urbana (SAMPAIO, 2013). Todavia, diferentemente do urbanismo tático, não são realizadas sob o pretexto de transformação urbana e com fins de bem coletivo.

Essa forma de apropriação informal de uso privado é fomentada pela falta de significado do espaço como bem comum e pela omissão do poder público em assumir o espaço como de sua responsabilidade. Assim como, pode ser impulsionada pelos planos e projetos urbanísticos que renegam a existência de determinados espaços. Conta, também, com a tolerância da população local e com a omissão dos órgãos fiscalizadores para se efetivar (SAMPAIO, 2013).

51 Devido, em especial, ao neoliberalismo aplicado à produção e à gestão das cidades, algumas intervenções não têm sido mais realizadas de maneira informal. Entretanto, o caráter social tem sido deixado, na maioria dos casos, em segundo plano. 0 poder público atualmente tende a se eximir da responsabilidade pelos resíduos urbanos e concede temporariamente o uso do espaço para determinadas atividades, dentre elas, as comerciais (NOGUEIRA, 2017).

Sendo assim, os espaços residuais têm sido potencializados e transformados, principalmente, através do capital privado, seja ele de grandes investimentos de um único provedor, ou proveniente de diversos pequenos atores, que representam uma microrresistência cotidiana para uso daquele espaço de forma coletiva. 

dois vieses: o viés do capital coletivo investido no local ou o viés de uso coletivo, mesmo que o capital seja proveniente de um único investidor. Frequentemente, o capital coletivo investido no local agregado à finalidade de uso coletivo do espaço representa formas de atração social mais eficazes, como, a título de exemplo, as feiras. A exemplificação demonstra que esse tipo de investimento, por diversas vezes, é impulsionado pela demanda da população.

Imagem 4 - Feira de antiguidades sob o antigo Elevado da Perimetral na Praça XV/RJ

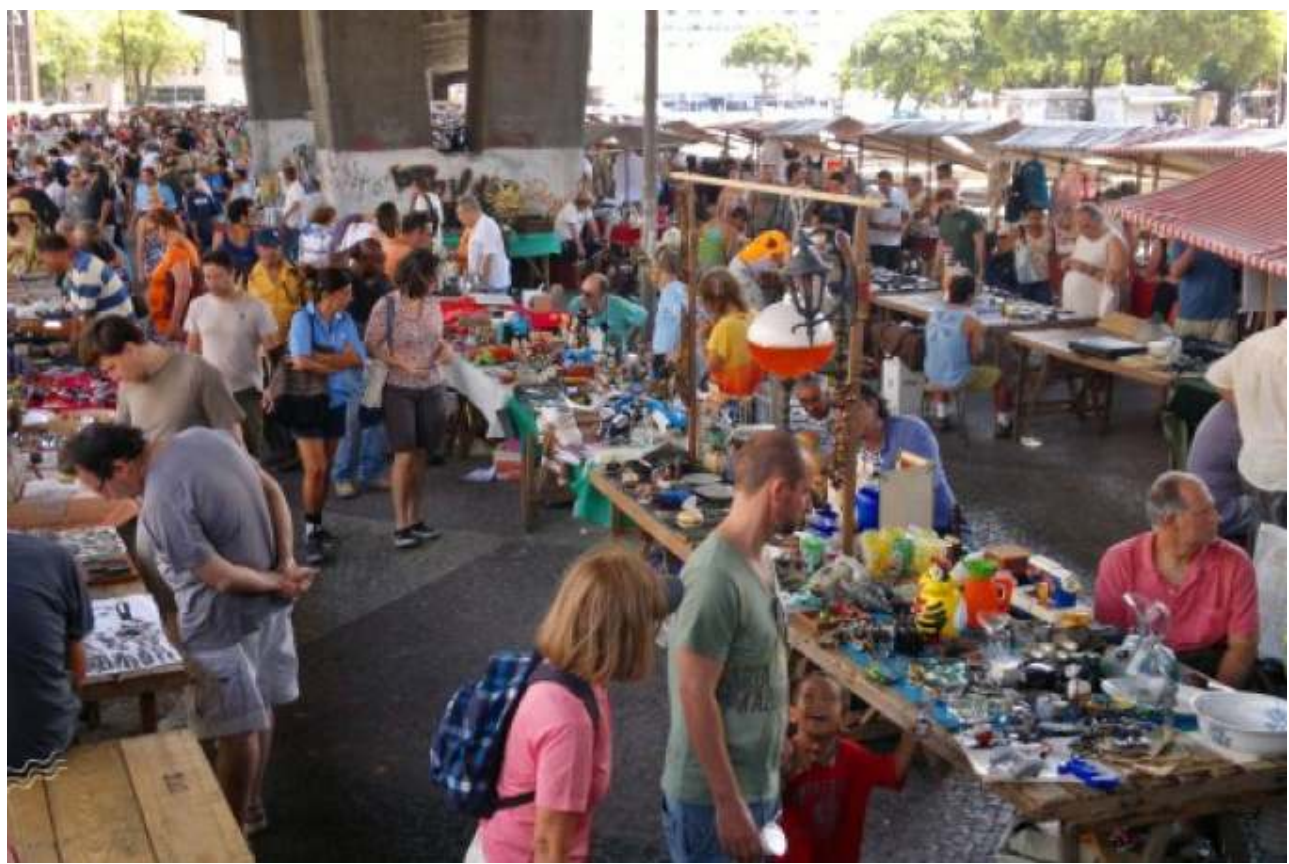

Fonte: <https://vejario.abril.com.br/cidades/feira-de-antiguidades-da-praca-xv-ganha-novas-regras/>

$\mathrm{Na}$ conjuntura da cidade neoliberal, apenas determinados espaços são eleitos para uso comercial sob a ótica dos interesses corporativos. Essa escolha não é aleatória. Certos espaços residuais mostram-se mais adequados que outros (SAMPAIO, 2013). A diferença trata-se, essencialmente, entre o espaço residual demonstrar sua potencialidade em ser espaço opaco ou espaço luminoso, apropriando-se dos conceitos de Milton Santos (1996).

espaços opacos, onde a pobreza e as classes sociais excluídasse instalam, são menos atrativos para maiores ou determinados investimentos comerciais. A diferença de valor agregado ao metro quadrado do solo, como espaço periférico ou central, impulsiona esse contraste. Contudo, inseridos nos espaços opacos de Santos (1999), ainda é possível encontrar espaços com maior ou menor atratividade corporativa. Os de maior atratividade podem ser apropriados com fins comerciais de pequeno porte ou simples, adequados à necessidade local. Esses espaços representam a microrresistência cotidiana.

Já os espaços residuais em "áreas luminosas" convivem sob a pressão do capital para o aproveitamento máximo de seu uso comercial. Não obstante, é notável a variação do nível de atratividade de um espaço residual para interesses corporativos de acordo com a relação entre este e seu entorno imediato. A relação entre centralidade, valor do solo urbano, amenidades e demanda é determinante para a seleção do espaço mais adequado. 
De todo modo, o comércio funciona como ponto de atração de usuários, transformando o espaço residual em espaço de permanência, seja de curto ou longo prazo. Por mais que o uso comercial possua horário determinado, ou seja, temporário, a apropriação do espaço residual através de interesses corporativos tende a resgatá-lo à dinâmica dos negócios urbanos da cidade capitalista.

\section{Considerações Finais}

Em função das reflexões apresentadas no desenvolvimento deste trabalho, nesta última seção são ressaltadas algumas inquietações quanto ao tema das paisagens urbanas comuns na cidade contemporânea. As questões analisadas quando associadas à subtração arbitrária de espaços públicos, a partir do caso da Praça Carlos Gianelli, ou mesmo aos espaços residuais na cidade contemporânea apresentam-se como discussão que se sustenta na definição de paisagens urbanas comuns.

Essas paisagens são submetidas a uma lógica de renovação em função da política neoliberal de produção do espaço. Por sua vez, essas dinâmicas capitalistas contemporâneas se apoiam em atores e práticas que se revelam, muitas vezes, como tentativas arbitrárias de reurbanização e ressignificação desses espaços, produzindo novas paisagens, usos e significados.

Por outro lado, paisagens submetidas às pressões corporativas parecem se despontar como elementos estratégicos à criação de novos simbolismos locais, os quais não podem ser desconsiderados no âmbito de um processo social e político de governança à luz do empresariamento urbano.

61 Ademais, a temática tratada neste trabalho traduz-se como repertório da cidade contemporânea, vivenciado por diferentes grupos sociais, explicitado na dialética entre relações público-privadas, e contribuindo por aguçar diferenças relacionadas aos modos de consumo, estilos de vida e relações de poder.

62 Longe de ser esgotada, a temática aqui discutida reascende as discussões em cima das pressões a que as paisagens urbanas comuns são submetidas na cidade neoliberal, propiciando um vasto campo de sugestões para estudos presentes e futuros.

\section{BIBLIOGRAFIA}

ARAUJO, Vitor; MELO, Hildete. O processo de esvaziamento industrial em São Gonçalo no século XX: auge e declínio da Manchester Fluminense. Cadernos do Desenvolvimento Fluminense, n. 4, pp. 65-87, 2014.

ASCHER, François. Os Novos Princípios do Urbanismo. São Paulo: Romano Guerra, 103p, 2010.

AUGUSTIN, J. Villes et culture, un nouveau rapportau monde. In: AUGUSTIN, J. La consommation comme loisir. Urbanisme, n. 319, pp. 74, 2001. 
BALBI, Thiago Machado. A vida, a morte e aquilo que sobra: os espaços residuais como elementos de uma ecologia comunicacional dos lugares da cidade. São Paulo, Tese de Doutorado em Comunicação e Semiótica. Programa de Estudos Pós-Graduados em Comunicação e Semiótica, Pontifícia Universidade Católica de São Paulo, 147p, 2017.

BAUMAN, Zygmunt. Modernidade Líquida. Rio de Janeiro: Jorge Zahar, 258p, 2001.

BAUMAN, Zygmunt. Vida Líquida. Rio de Janeiro: Jorge Zahar, 210p, 2007.

BORDE, Andrea. Vazios urbanos: perspectivas contemporâneas. Rio de Janeiro, Tese de Doutorado em Urbanismo. Programa de Pós-Graduação em Urbanismo, Universidade Federal do Rio de Janeiro, $226 \mathrm{p}, 2006$.

BORJA, Jordi. Espaço público, condição da cidade democrática: a criação de um lugar de intercâmbio. Arquitextos, São Paulo, a. 06, n. 072.03, Vitruvius, mai. 2006. Disponível em: <http:// www.vitruvius.com.br/revistas/read/arquitextos/06.072/353>. Acesso em: 20 mar. 2019.

BORJA, Jordi; MUXÍ, Zaida. El espacio público: Ciudad y ciudadanía. Barcelona: Editorial Electa, 415p, 2001.

BOURDIEU, Pierre. A miséria do mundo. Rio de Janeiro: Vozes, 747p, 1997.

CAMPAGNANI, Mario. Uma praça cercada de polêmica em Alcântara. Extra. Rio de Janeiro, 19 mai. 2011. Disponível em: <https://extra.globo.com/noticias/rio/uma-praca-cercada-de-polemica-emalcantara-1843154.html> Acesso em: 27 fev. 2019.

CORRÊA, Roberto Lobato. O espaço urbano. São Paulo: Editora Ática, 94p, 1993.

CORRÊA, Roberto Lobato. Formas simbólicas espaciais: o shopping center. In: CORRÊA, Roberto Lobato; ROSENDAHL, Zeny. (Orgs.). Geografia Cultural: uma antologia (vol. II). Rio de Janeiro: EdUERJ, pp. 91-100, 2013.

COSGROVE, Denis. Social Formation and Symbolic Landscape. Londres: Croom Helm, 293p, 1984.

FERRARA, Lucrécia D’Aléssio. Os significados urbanos. São Paulo: EdUSP, 185p, 2000.

FRÚGOLI JR., Heitor. São Paulo: espaços públicos e interação social. São Paulo: Marco Zero, 112p, 1995. GEHL, Jan. La humanización del Espacio Urbano - La vida social entre los edifícios. Barcelona: Editorial Reverté S.A., 217p, 2009.

HARVEY, David. A condição pós-moderna. São Paulo: Loyola, 352p, 2008.

HARVEY, David. O Enigma do Capital e as crises do capitalismo. São Paulo: Boitempo, 224p, 2011.

KOOLHAAS, Rem. Rem Koolhaas: três textos sobre a cidade. Barcelona: Editorial Gustavo Gili, 112p, 2010.

LYNCH, Kevin. The image of the city. Cambridge: MIT Press, 194p, 1960.

NOGUEIRA, Pedro. Urbanismo tático e intervenções urbanas: aderências e deslizamentos. Arcos Design, v. 10, n. 1, pp. 89-101, 2017.

PEREIRA, Margareth. Dimensões da Experiência: Espaço Público, Alteridade e Lugar. In: RIBEIRO, Ana Clara Torres; VAZ, Lilian Fessler; SILVA, Maria LaisPereira da (Orgs.). Leituras da Cidade. Rio de Janeiro: Letra Capital, pp.39-42, 2012.

QUEIROGA, Eugênio; BENFATTI, Denio. Sistemas de espaços livres urbanos: construindo um referencial teórico. Paisagem e Ambiente, n. 24, pp. 81-87, 2007. 
SAMPAIO, Sanane. Grandezas do Ínfimo: espaços residuais em Salvador. Salvador, Dissertação de Mestrado em Arquitetura e Urbanismo. Programa de Pós-Graduação em Arquitetura e Urbanismo, Universidade Federal da Bahia, 122p, 2013.

SANTOS, Carlos Nelson Ferreira dos. A cidade como um jogo de cartas. Niterói: EDUFF/São Paulo: Projetos Editores, 192p, 1988.

SANTOS, Milton. A Natureza do Espaço - técnica e tempo, razão e emoção. São Paulo: Hucitec, 308p, 1996.

SENNETT, Richard. O declínio do homem público: as tiranias da intimidade. São Paulo: Companhia das Letras, 447p, 2001.

SERPA, Angelo. O espaço público na cidade contemporânea. São Paulo: Contexto, 205p, 2007.

SILVEIRA, Sergio; SAVAZONI, Rodrigo. O Conceito de Comum: Apontamentos introdutórios. Liinc em Revista, v.14, n.1, pp. 05-18, 2018.

SOLÀ-MORALES, Ignasi de. Territorios. Barcelona: Editorial Gustavo Gili, 208p, 2003.

SORKIN, Michael. See you in Disneyland. In: SORKIN, Michael (Ed.). Variations on a theme park: the new american city and the end of public space. New York: Hill and Wang, pp. 205-232, 1992.

TAVARES, Valentim. Paisagens do despertencimento: o caso da praça Carlos Gianelli no centro urbano de Alcântara, São Gonçalo-RJ. Niterói, Dissertação de Mestrado em Arquitetura e Urbanismo. Programa de Pós-Graduação em Arquitetura e Urbanismo, Universidade Federal Fluminense, 236p, 2013.

\section{RESUMOS}

As cidades contemporâneas estão se tornando cada vez mais diversificadas e multiculturais. A tendência observada em espaços urbanos que enfrentam desafios sociais vem por inspirar novos modelos para as políticas públicas municipais. Este artigo antecipa uma discussão sobre a análise sensível do espaço, sua apropriação, dinamismos, conflitos e atores, além de inquietações do cotidiano. A revisão bibliográfica baseou-se em diálogo teórico sobre a compreensão do espaço público como elemento estruturante da paisagem. A tese da mutabilidade das paisagens na cidade contemporânea neoliberal é reafirmada pela valorização das paisagens urbanas comuns submetidas a constante pressão de interesses corporativos. Essa análise é sustentada pelo modo com o qual a cidade contemporânea lida com seus espaços urbanos residuais e é submetida a atos de mercantilização de seus espaços públicos.

Les villes contemporaines sont de plus en plus diverses et multiculturelles. La tendance observée dans les espaces urbains confrontés à des défis sociaux inspire de nouveaux modèles pour les politiques publiques municipales. Cet article prévoit une discussion sur l'analyse sensible de l'espace, son appropriation, ses dynamiques, ses conflits et ses acteurs, ainsi que ses préoccupations quotidiennes. La revue bibliographique était basée sur un dialogue théorique sur la compréhension de l'espace public en tant qu'élément structurant du paysage. La thèse de la mutabilité des paysages dans la ville néolibérale contemporaine est réaffirmée par la valorisation des paysages urbains communs soumis à une pression constante des intérêts des entreprises. Cette analyse est étayée par la manière dont la ville contemporaine traite ses espaces urbains résiduels et est soumise à des actes de marchandisation de ses espaces publics.

Las ciudades contemporáneas se están volviendo cada vez más diversificadas y multiculturales. La tendencia observada en espacios urbanos que enfrentan desafíos sociales viene por inspirar nuevos modelos para las políticas públicas municipales. Este artículo anticipa una discusión sobre 
el análisis sensible del espacio, su apropiación, dinamismos, conflictos y actores, además de inquietudes de lo cotidiano. La revisión bibliográfica se basó en un diálogo teórico sobre la comprensión del espacio público como elemento estructurante del paisaje. La tesis de la mutabilidad de los paisajes en la ciudad contemporánea neoliberal es reafirmada por la valorización de los paisajes urbanos comunes sometidos a constante presión de intereses corporativos. Este análisis es sostenido por el modo con el que la ciudad contemporánea trata con sus espacios urbanos residuales y es sometida a actos de mercantilización de sus espacios públicos.

The contemporary cities are becoming increasingly diverse and multicultural. The trend observed in urban spaces that face social challenges comes to inspire new models for municipal public policies. This paper anticipates a discussion about the sensitive analysis of space, its appropriation, dynamics, conflicts and actors, as well as daily concerns. The literature review was based on a theoretical dialogue about the understanding of the public space as a landscape's structuring element. The thesis of the mutability of landscapes in the contemporary neoliberal city is reaffirmed by the valuation of the common urban landscapes submitted to constant pressure of corporate interests. This analysis is supported by the way in which the contemporary city deals with its residual urban spaces and it is forced to acts of public spaces commodification.

\section{ÍNDICE}

Mots-clés: paysages urbains, espace public, dynamique néolibérale, ville contemporaine.

Keywords: urban landscapes, public space, neoliberal dynamics, contemporary city.

Palavras-chave: paisagens urbanas, espaço público, dinâmicas neoliberais, cidade contemporânea.

Palabras claves: paisajes urbanos, espacio público, dinámicas neoliberales, ciudad contemporánea.

\section{AUTORES}

\section{JEFFERSON TOMAZ DE ARAÚJO}

Arquiteto e Urbanista (EAU/UFF). Mestrando do Programa de Pós-Graduação em Arquitetura e Urbanismo (UFF). Universidade Federal Fluminense.

E-mail: jeffersontomaz@id.uff.br

\section{KARINA MARTINS DE SOUZA}

Arquiteta e Urbanista (FAU/UFRJ). Mestranda do Programa de Pós-Graduação em Arquitetura e Urbanismo (UFF). Universidade Federal Fluminense.

E-mail: karinams05@hotmail.com

\section{ELOISA CARVALHO DE ARAUJO}

Pós-Doutoranda do Programa de Pós-Graduação em Urbanismo (UFRJ). Professora do Programa de Pós-Graduação em Arquitetura e Urbanismo e da Escola de Arquitetura e Urbanismo (UFF). Universidade Federal Fluminense.

E-mail: eloisa.araujo@gmail.com 